\title{
O Romanceiro Brasileiro: Pequeno Catálogo
}

\section{INTRODUÇÃO}

O romanceiro brasileiro começou a ser estudado por volta de 1853 , data de um manuscrito de Inácio Raposo em que se reunem oito romances sob o título de Romanceiro Tradicional do Brasil ${ }^{1}$. Como se sabe, fora Almeida Garrett quem dera a conhecer que os velhos romances da Idade Média e do Renascimento tinham sido perpetuados na memória do povo, iniciando todos os trabalhos de recolha posteriores, tanto em Portugal como em Espanha. Garrett começou a recolher romances em 1823 ou 1824, publicou dois em 1828 como apêndice à $A d o z i n d a^{2}$, e os três tomos do seu Romanceiro surgiram em 1843 (I) e 1851 (II-III) ${ }^{3}$. Reunido apenas dois anos depois, o manuscrito de Inácio Raposo prova que o exemplo do pioneiro português foi seguido no Brasil bastante antes do que em Portugal, onde o primeiro continuador de Garrett, Teófilo Braga, só viria a publicar o seu Romanceiro Geral em $1867^{4}$.

Como o manuscrito de Inácio Raposo permaneceu inédito, é a Celso de Magalhães que cabe a honra de iniciar o estudo do romanceiro no Brasil, ao editar os primeiros romances daquele país em $1873^{5}$. O trabalho de Celso de Magalhães é também pioneiro no sentido de que, além do

1 V. Lluís da] C[ÂMARA] C[ASCUDO], "Romanceiro", Dicionário de Literatura (Portuguesa, Brasileira, Galega), org. de Jacinto do Prado Coelho (Porto: Figueirinhas, 1982), vol. III, 961.

2 V. José Joaquim Dias Marques, "Nota Sobre o Início da Recolha do Romanceiro da Tradição Oral Moderna", Boletim de Filologia, 32 (1992), 71-82.

3 Almeida GARRET, Romanceiro, ed. Fernando de Castro Pires de Lima (Lisboa: FNAT, 1963), 3 vols. Em 1832, na Ilha Terceira, Garrett tinha recolhido romances duma criada (escrava?) mulata brasileira de sua irmã $(I, 35)$ mas, se os chegou a utilizar, não apontou nenhumas variantes brasileiras nas notas de roda-pé, como faz frequentemente com as versões de varias províncias e dos Açores.

4 Teófilo BRAGA, Romanceiro Geral Coligido da Tradiçâo (Coimbra: Imprensa da Universidade, 1867).

5 Celso de Magalhảes, A Poesia Popular Brasileira, org. de Bráulio do Nascimento (Rio de Janeiro: Biblioteca Nacional, 1973). 
mencionado livro de Teófilo Braga, só tinham surgido mais duas colectâneas de vulto em Portugal: os Cantos Populares do Arquipélago Açoriano, também de Teófilo (1869) ${ }^{6}$, e o Romanceiro do Algarve, de Estácio da Veiga $(1870)^{7}$.

Celso de Magalhães investigou a tradição oral nos estados de Pernambuco, Baía e Maranhão. A colecção de Sílvio Romero, dedicada ao Sergipe e ao Rio de Janeiro, apareceu dez anos depois (1883) ${ }^{8}$. Em 1908, Pereira da Costa publicou mais romances de Pernambuco ${ }^{9}$. Outros investigadores têm desde então dedicado colectâneas relativamente extensas a várias partes do país. Citemos as de Boiteux (1944; Santa Catarina) ${ }^{10}$, Santos Neves (1961; Espírito Santo) ${ }^{11}$, Lopes (1967; Maranhão) ${ }^{12}$, Tavares de Lima (1971; São Paulo, Alagoas, Mato Grosso, Baía, Sergipe, Paraná, Santa Catarina, Rio de Janeiro, Minas Gerais) ${ }^{13}$, Calasans Brandão da Silva, Santana Braga e Campos Tourinho (1972; Baía) ${ }^{14}$, Silva Lima (1977; Sergipe) ${ }^{15}$, e Vilela (1983; Alagoas) ${ }^{16}$. Mais recentemente, Doralice Fernandes Xavier Alcoforado e María del Rosario Suárez Albán investiga-

6 Braga, Cantos Populares do Arquipélago Açoriano (Porto: Livraria Nacional, 1869).

7 S[ebastião] P[hilippes] M[artins] Estácio DA VEIGA, Romanceiro do Algarve (Lisboa: Joaquim Germano de Sousa Neves, 1870).

* Sílvio Romero, Cantos Populares do Brasil, acompanbados de introdução e notas comparativas por Teófilo Braga (Lisboa: Nova Livraria Internacional, 1883), 2 vols.

9 Francisco Augusto PEREIRA DA COSTA, Folclore Pernambucano (Rio de Janeiro: Livraria J. Leite, 1908).

10 Lucas Alexandre BoIteuX, "Poranduba Catarinense”, Revista do Instituto Histórico e Geográfico Brasileiro, 184 (1944), 1-92; reimp. em livro: Poranduba Catarinense (Florianópolis: Comissão Catarinense de Folclore, 1957).

1 Guilherme SANTOS NEVES, "Presença do Romanceiro Peninsular na Tradição Oral do Brasil., Revista Brasileira de Folclore, 1 (1961), 44-62.

12 António LOPES, Presença do Romanceiro. Versōes Maranbenses (Rio de Janeiro: Editora Civilização Brasileira, 1967).

13 Rossini TAvares de Lima, Romanceiro Folclórico do Brasil (São Paulo-Rio de Janeiro: Irmãos Vitale, 1971).

1* José Calasans Brandão da Silva, Júlio Santana Braga e María Antonieta Campos TOURINHO, Folclore Geo-Histónico da Babia e Seu Recôncavo (Rio de Janeiro: Campanha de Defesa do Folclore Brasileiro, 1972).

15 Jackson da SILVA LIMA, O Folklore em Sengipe, 1: Romanceiro (Rio de JaneiroBrasília: Livraria Editora Cátedra-Instituto Nacional do Livro, 1977).

16 José Aló́sio BRANdão VIlela, Romanceiro Alagoano, ed. Maria Thereza Wucherer Braga, Bráulio do Nascimento, Théo Brandão e Maria Thereza Ribeiro Massow (Maeció: Edufal, 1983). 
ram a tradição oral da Baía ${ }^{17}$, coligindo também nove romances de duas informantes galegas ${ }^{18}$.

Embora incompleta, esta lista já dá uma boa ideia da importância da contribuição brasileira para o estudo do romanceiro ${ }^{19}$. A tradição oral portuguesa tem sido investigada ainda com maior vigor, sendo de destacar as recolhas levadas a cabo nos últimos anos por Joanne Purcell, Pere Ferré, Vanda Anastácio, José Joaquim Dias Marques, Ana Maria Martins, António Maria Mourinho, Pedro da Silveira, Berta Madureira Beça e José Dias da Costa, Samuel G. Armistead, Israel J. Katz, e Candace Slater. O autor destas linhas também reuniu várias colecções, e Maria Aliete Dores Galhoz organizou recentemente um monumental romanceiro que reune materiais previamente inéditos, assim como romances incluídos em teses apresentadas à Universidade de Lisboa ${ }^{20}$. Algumas grandes colecções ainda permanecem inéditas, mas existem vários milhares de romances portugueses e brasileiros publicados, quer em forma de livro, quer dispersos em revistas, algumas de acesso relativamente difícil ${ }^{21}$.

O Romanceiro Tradicional Português de João David Pinto-Correia contribuiu para ordenar estes materiais, dado que contém uma excelente introdução e uma grande selecção proveniente de várias fontes, constitu-

17 Doralice Fernandes Xavier Alcoforado e María del Rosario Suárez Albán, .O Romanceiro Baiano*, introdução de Idelette Muzart Ferreira dos Santos, Estudos Linguísticos e Literários, 7 (Out. 1988), 47-130.

18 Doralice Fernandes Xavier Alcoforado e María del Rosario Suárez Albán, “O Romanceiro Galego", Estudos Literários e Linguisticos, 7 (Out. 1988), 131-46. Para um panorama mais pormenorizado das investigações levadas a cabo no Brasil até 1970, V. Bráulio do NASCimento, "Pesquisa do Romanceiro Tradicional no Brasil", El romancero en la tradición oral moderna: $1 .^{\text {er }}$ Coloquio internacinal, org. de Diego Catalán, et al. (Madrid: CSMP-Universidad de Madrid, 1972), 65-83.

19 Para mais bibliografia brasileira, veja-se, por agora, o meu Romanceiro da Provincia de Trás-os-Montes (Distrito de Bragança), coligido com a colaboraçào de MariaJoão Câmara Fontes, prefácio de Samuel G. Armistead e Joseph H. Silverman, transcrições musicais de Israel $\mathbf{J}$. Katz, 2 vols., Acta Universitatis Conimbrigensis (Coimbra: Universidade, 1987), II, 1408-10.

20 Maria Aliete DOREs GALHOZ, Romanceiro Popular Português (Lisboa: INIC, 198788), 2 vols. Sobre as recolhas dos últimos anos, V. I, xix-xxiv, II, xi, e -Resenha sobre a Actividade Editorial Romancística em Portugal nos Últimos Anos", Revista Lusitana (Nova Série), 8 (1987), 177-84, também da autora. As recolhas dos três últimos norteamericanos acima citados foi reunida no Cancioneiro Tradicional de Trás-os-Montes, textos recolhidos por Samuel G. Armistead, Israel J. Katz, Zilia Osório de Castro e Candace Slater, transcrições musicais de Israel J. Katz, org. de Samuel G. Armistead e de Manuel da Costa Fontes, em colaboração com os colectores (manuscrito).

21 Para mais bibliografia portuguesa, V. por agora o meu Romanceiro da Provincia de Träs-os-Montes, II, 1397-1408. 
indo a primeira obra do género em Portugal ${ }^{22}$. Contudo, ainda faltava um catálogo que classificasse a temática completa do romanceiro português, tomando em conta todas ou quase todas as versões publicadas. Empreendi a tarefa há alguns anos, e o resultante O Romanceiro Português e Brasileiro: Índice Temático e Bibliográfico está praticamente pronto para o prelo ${ }^{23}$.

Esta obra, que é essencialmente bilingue (português e inglês), adapta o sistema utilizado por Samuel G. Armistead no seu grande catálogo dos romances sefarditas conservados no Arquivo Menéndez Pidal (Madrid) ${ }^{24}$, arrumando os romances em 26 grupos, um para cada letra do alfabeto. Os primeiros grupos classificam os poemas segundo a sua origem (A. Épicos; B. Carolíngios; C. Históricos; E. Bíblicos), e o resto do sistema é temático, organizando os romances segundo o tema ou assunto principal (H. Presos e Cativos; I. Regresso do Marido; etc.). As Canções Cumulativas (Y) e alguns dos poemas em $Z$. Romances e Canções Infantis não são verdadeiros romances, mas dão uma ideia mais completa do conteúdo da tradição oral. Embora tradicionalizados, vários poemas têm a sua origem na literatura de cordel, que é geralmente mais moderna. Este catálogo apresenta um exemplo de cada romance--e por vezes dois ou três, quando há diferenças notáveis no mesmo tema--, seguido por um resumo em inglês e uma bibliografia pan-ibérica cuja ordem é a seguinte: Portugal, Brasil, Galiza, Castela, Catalunha, Sefarditas, América Espanhola, Tradição Antiga, Outras Obras. As versões portuguesas e brasileiras com transcrições musicais são identificadas com um $(\mathrm{m})$. Também se inclui uma secção intitulada Outros Países, de carácter pan-europeu, que se deve à colaboração de Samuel G. Armistead. Sob Outras Obras, faz-se referência às quatro indispensáveis bibliografias do Professor Armistead, as primeiras três das quais são críticas, incluindo resumos para cada entrada ${ }^{25}$. Este

22 João David PINTO-CorReia, Romanceiro Tradicional Português, Textos Literários 36 (Lisboa: Comunicçào, 1984). A tradição espanhola já contava com várias obras semelhantes. V. por ex., C. CouIN SmITH, Spanish Ballads (Oxford: Pergamon Press, 1964); Giuseppe Di STEFANO, El Romancero: Estudios, notas y comentarios de texto (Madrid: Narcea, 1973); Mercedes Díaz Roig, El Romancero viejo (Madrid: Cátedra, 1981); Michelle Débax, Romancero (Madrid: Alhambra, 1982).

23 Será provavelmente publicado nas Acta Universitatis Conimbrigensis.

24 Samuel G. ARMISTEAD, El romancero judeo-español en el Archivo Menéndez Pidal (Catálogo-indice de romances y canciones) (Madrid: CSMP, 1978), 3 vols.

25 Sanuel G. ARMISTEAD, A Critical Bibliography of the Hispanic Ballad in Oral Tradition (1971-79),, The Hispanic Ballad Today: History, Comparativism, Critical Bibliography, 2nd International Symposium, University of California, Davis, org. de Samuel G. Armistead et al. (Madrid: CSMP-University of California-Gredos, 1979), 
catálogo, que também apresenta transcrições musicais seleccionadas por Israel J. Katz, termina com vários índices destinados a facilitar a sua consulta: 1. Correspondências com o romanceiro sefardita; 2. Correspondências com o Indice General del Romancero ${ }^{26}$; 3 . Correspondências com o romanceiro galego e leonês; 4. Distribuição pan-ibéri$\mathrm{ca}^{27} ; 5$. Distribuição luso-brasileira ${ }^{28} ; 6$. Correspondências com o conto popular; 7. Romances com paralelos pan-europeus; 8. Romances ao divino; 9. Títulos portugueses; 10. Títulos espanhóis-portugueses; 11. Títulos portugueses-espanhóis; 12. Títulos pan-europeus ${ }^{29} ; 13$. Títulos em inglês; 14. Nomes próprios; 15. Primeiros versos portugueses; 16. Primeiros versos das versões antigas; 17 . Transcrições musicais luso-brasileiras; e 18. Transcrições musicais incluídas nesta obra.

Obviamente, O Romanceiro Português e Brasileiro inclui a temática recolhida no Brasil, mas no contexto mais amplo da tradição oral portuguesa, de modo que esses materiais se acham dispersos através da obra. O catálogo brasileiro apresentado neste trabalho tem a vantagem de reunir essa temática sucintamente num só lugar, proporcionando assim um melhor panorama da tradição oral do Brasil. É possível extrair alguns dados interessantes por meio de uma comparação superficial dos dois catálogos mas, antes de prosseguir, é preciso prestar um esclarecimento.

O Romanceiro Português e Brasileiro inclui 21 exemplos de poemas não tradicionais ou então de tradicionalidade suspeita, compostos na vasta maioria por escritores românticos que tratavam de imitar a poesia popular.

199-310; id., "Bibliografía crítica del romancero (1979-1983)" (no prelo); id., •Bibliografía crítica del romancero (1984)", Actas del Congreso Romancero-Cancionero UCLA (1984), org. de Enrique Rodríguez Cepeda e Samuel G. Armistead, 2 vols. (Madrid: José Porrúa Turanzas, 1990), II, 447-530; id., *Bibliografía del romancero (1985-1987)", El Romancero: Tradición y pervivencia a fines del siglo XX. Actas del IV Coloquio Internacional del Romancero (Sevilla-Puerto de Santa María-Cádiz, 23-26 de junio de 1987), org. de Pedro M. Piñero et al. (Sevilla-Cádiz: Fundación Machado-Universidad de Cádiz, 1989), 749-89.

26 Trata-se de um sistema de classificação para todo o romanceiro pan-ibérico que está sendo elaborado pelo Seminário Menéndez Pidal. Esse sistema utiliza-se em Diego Catalán, J. Antonio Cid, Beatriz Mariscal, Flor Salazar, ana Valenciano e Sandra ROBERTSON, CGR: Catálogo general del romancero. El romancero pan-bispánico: Catálogo general descriptivo (Madrid: SMP, 1982-88), 4 vols., obra que contém descrições extremamente promenorizadas de 82 -Romances de contexto histórico nacional", incluindo todos os romances baseados nas canções de gesta peninsulares, romances historicos, e romances mouriscos.

27 Segue a ordem geográfica utilizada na bibliografía acima descrita.

28 Trás-os-Montes, Algarve, Açores, Madeira, Brasil.

29 Este índice será preparado pelo Prof. Armistead. 
Esses poemas são sempre precedidos por um asterisco. Este catálogo também contém alguns poemas exclusivamente portugueses possivelmente mais recentes que, por essa razão, talvez nunca tenham sido transmitidos para o Brasil. Por outras palavras, a comparação que se segue é aproximativa. Todavia, se excluirmos os 21 textos acima indicados, o catálogo luso-brasileiro compreende um total de 304 poemas, ao passo que o catálogo brasileiro tem 89. É particularmente notável a ausência do grupo A, com 14 romances baseados na canção de gesta peninsular. Nenhum deles se tradicionalizou no Brasil. O catálogo brasileiro também omite os grupos D (Mourisco; só há um em Portugal), F (Clássicos; 4 em Portugal), G (Aventuras do Herói Jovem 1 em Portugal), e outros grupos reunem um número de romances bastante menor.

Isto significa que a teoria das zonas laterais, segundo a qual essas áreas são mais conservadoras ( $\mathrm{e}$, por conseguinte, mais ricas) do que as inovadoras zonas centrais, as quais se caracterizam mais pela disseminação, deve ser aplicada com grande cuidado. Referindo-se especificamente ao Brasil, Menéndez Pidal escreveu em 1957 que “o esta teoría es falsa, o el Brasil tiene todavía que enriquecer el romancero con valiosos arcaísmos" ${ }^{30}$. Hoje já se coligiram romances através de todo o país, descobrindo-se mesmo uma versão de X1. Nau Catrineta entre os índios do Amazonas ${ }^{31}$. Contudo, as regiões mais conservadoras encontram-se em Portugal: a isolada província nordestina de Trás-os-Montes, cuja tradição oral é, de longe, a mais rica do país, seguida pelos ainda mais isolados arquipélagos da Madeira e dos Açores. O mesmo acontece com a Espanha em relação aos países de língua espanhola da América Latina. Apesar da importância da contribuição latino-americana, a tradição oral da Espanha mantém-se com muito maior vigor. Portanto, pelo menos no mundo luso-hispânico, a teoria das áreas laterais aplica-se somente às regiões mais isoladas de Portugal e da Espanha, e não às suas antigas colónias.

No entanto, o catálogo que se segue demonstra que a tradição brasileira é extremamente importante, partilhando com Portugal muitos romances raros que desapareceram das tradições hispânicas. Frei Ambrósio de

30 Ramón Menéndez PIDAl, “A propósito del 'Romanceiro Português' de J. Leite de Vasconcellos", Actas: III Coloquio Internacional de Estudos Luso-Brasileiros, 2 vols. (Lisboa: Imprensa de Coimbra, 1959), I, 493-99; reimp. em José Leite de Vasconcellos, Romanceiro Português, 2 vols., Acta Universitatis Conimbrigensis (Coimbra: Universidade, 1958-60), I, xi-xxi: p. xxi.

31 Bráulio do NASCimenTo, "Um Romance Tradicional Entre Índios do Amazonas, no Século XX", El romancero boy: Nuevas fronteras, $2 .^{\circ}$ Coloquio Internacional, University of California, Davis, org. de Antonio Sánchez Romeralo et al. (Madrid: CSMP-University of California-Gredos, 1979), 115-24. 
Montesino compôs o histórico C4. Morte do Príncipe D. Afonso em espanhol, logo após o acidente que roubou a vida ao filho e herdeiro de $D$. João II em 1491, mas hoje em dia o romance é exclusivamente português e brasileiro ${ }^{32}$. O mesmo se passa com C7. Batalba de Lepanto, que perpetua a grande vitória naval de D. João de Áustria contra os Turcos em Lepanto $(1571)^{33}$. S2. Lizarda constitui uma das metamorfoses da Tragicomedia de don Duardos (c. 1525), composta em castelhano por Gil Vicente ${ }^{34}$. X20. Vida de Freira é um poema de provada origem quinhentista castelhana ${ }^{35}$, e o seu correspondente masculino, X21. Vida de Frade, talvez também seja bastante antigo. É possível que Z2. Barca Bela, contrafacção do quinhentista Conde Arnaldos, tenha tido a sua origem em Portugal. Apesar da falta de versões antigas, é quase certo que Barca Bela já era corrente naquele país em fins do século XV e princípios do século XVI, dado que inspirou Remando Vão Remadores, romance composto por Gil Vicente para principiar o seu Auto da Barca do Purgatório (c. 1517) ${ }^{36}$. Como U35. Santo António e a Princesa de Leão foi composto por um português, Francisco Lopes, em $1620^{37}$, não admira que não se tenha tradicionalizado em castelhano. Trata-se de um poema bastante raro, tendo sido recolhido somente no Algarve, nos Açores, e no Brasil. U37. Santa Teresa e o Pobrezinbo é sobre uma santa castelhana, Teresa de Ávila. Não é provável que seja de origem portuguesa mas, que eu saiba, nunca foi descoberto nas outras subtradições.

A tradição brasileira também partilha com a portuguesa outros romances que, apesar de representados nas tradições hispânicas, são extrema-

32 R. MEnÉndez PIDAl, Cómo vivió y cómo vive el Romancero, pp. 407-15; V. também $\mathrm{O}$ indispensável estudo de Paul Bénichou, El romance de la muerte del príncipe de Portugal en la tradición moderna", Nueva Revista de Filología Hispánica, 24 (1975), 113-24.

33 V. M. da Costa Fontes, "The Batalba de Lepanto in the Portuguese Oral Tradition, Hispanic Review, 47 (1979), 487-503.

34 V. COSTA FONTES, "Lizarda: A Rare Vicentine Ballad in California", Romance Pbilology, 32 (1978-79), 308-14.

35 V. COSTA FONTES, "Vida de Freira en la tradición oral luso-brasileira", Estudios de folklore y literatura dedicados a Mercedes Diaz Roig, org. de Beatriz Garza Cuarón e Yvette Jiménez de Báez, Estudios de Lingüística y Literatura 20 (México, D.F.: El Colegio de México, 1992), 641-65; -A Transmissão Oral e as Progressivas Modificações Éticas e Estéticas: O Caso de Vida de Freira. Atlântida, 35 (1990), 17-54 constitui uma versão um pouco mais extensa daquele trabalho.

36 V. COSTA FONTES, Barca Bela in the Portuguese Oral Tradition", Romance Pbilology, 37 (1983-84), 282-92.

37 Té́filo BragA, Romanceiro Geral Português, 2." ed., 3 vols. (Lisboa: Manuel Gomes, 1906, 1907; J. A. Rodrigues, 1909), III, 157-59. 
mente raros. O carolíngio B10. Floresvento, documentado no Brasil por meio de uma contaminação com N1. Veneno de Moriana, existe na tradição sefardita por meio de fragmentos contaminados com outro romance, e a única versão galega conhecida segue as de Trás-os-Montes em todos os pormenores ${ }^{38}$. Os carolíngios B1. Morte de D. Beltrão e B2. Conde Claros e a Princesa Acusada escasseiam nas outras subtradições ${ }^{39}$. M9. Conde da Alemanha, que costumava ser considerado exclusivamente lusobrasileiro e sefardita, foi recentemente descoberto em território castelhano, mas numa versão em língua portuguesa. O raro N4. As Três Irmãzinhas também se canta em Castela, e O5. A Romeira e o Cavaleiro existe num número muito reduzido de versões galegas e castelhanas.

Note-se que, embora relativamente raros no mundo hispânico, alguns romances são relativamente frequentes na tradição luso-brasileira: $\mathrm{H} 3$. $O$ Cativo, 17. O Conde Flores, K1. Donzela que se Fina de Amor, T2. A Aposta Ganha, U21. Paixão do Redentor e V2. D. Aleixo. N1. Veneno de Moriana, que pouco se canta no mundo hispânico--parece que nem chegou a tradicionalizar-se na América espanhola--é um dos romances mais conhecidos em Portugal e no Brasil.

Curiosamente, X26. A Filha do Rei de Espanba é também corrente entre os sefarditas, apesar de constituir a adaptação relativamente recente duma canção francesa ${ }^{40}$. O pan-hispânico Mirandum só foi traduzido no Brasil; em Portugal canta-se só em mirandês. J3. Afonso XII, adaptação do antigo J2. A Apariçâo, é corrente em todo o mundo de língua espanhola com excepção da tradição sefardita, mas a única versão portuguesa que consegui encontrar é brasileira. J12. Eu Entrei pelo Mar Dentro e K11. Felizardo são romances relativamente modernos que só existem no Brasil, onde também parecem ter sido compostos.

Este breve panorama ficaria incompleto se omitisse a importante contribuição de Bráulio do Nascimento, crítico de renome internacional a quem devemos valiosos estudos de carácter teórico, a re-edição do romanceiro de Celso de Magalhães, e uma vasta e indispensável bibliografia do folclore brasileiro ${ }^{+1}$.

* V. Costa Fontes, "A Sephardic Vestige of the Ballad Floresvento, La Corónica, 10 (1982), 196-201; "The Ballad of Floresvento and Its Epic Antecedents", Kentucky Romance Quarterly, 32 (1985), 309-19.

39 Sobre o último, V. Judith SEEGER, Count Claros: Study of a Ballad Tradition. The Albert Bates Lord Studies in Oral Tradition (New York-London: Garland, 1990).

+) V. Samuel G. Armistead e Joseph H. Silverman, "Uma Canção Francesa na Tradiçào Brasileira: A Filha do Rei da Espanhà, Ciência e Trópico, 6 (1978), 315-16.

${ }^{4}$ V., por ex., Bráulio do NAscimento, „Eufemismo e Criaçào Poética no Romanceiro Tradicional", El Romancero en la tradición oral moderna: 1 . $^{\text {er }}$ Coloquio Internaci- 
Como todas as províncias de Portugal exportaram romances para o Brasil, é geralmente impossível determinar a região de origem da maioria dos romances que se cantam nesse país. Note-se porém que, embora originalmente continentais, o histórico C4. Morte do Príncipe D. Afonso e o vicentino S2. Lizarda são hoje exclusivamente açorianos e madeirenses, e que as versões brasileiras se parecem muito com as insulanas. Por conseguinte, não há dúvida de que esses romances passaram para o Brasil graças a povoadores ou emigrantes das Ilhas.

Todos os especialistas sabem perfeitamente bem que a nobre tradição romancística oralmente transmitida da Idade Média e Renascimento aos nossos dias se extinguirá praticamente dentro de uma ou duas geraçôes devido à rádio, à televisão, à crescente urbanização do campo, e a outras pressões da vida moderna. Os jovens já não têm interesse em aprender os velhos romances com os pais, avós, e ainda menos com os vizinhos, os quais começam a esquecer os seus repertórios por estarem a desaparecer as actividades familiares e comunitárias em que costumavam cantá$\operatorname{los}^{42}$. Este fenómeno é mais acentuado no Brasil do que em Portugal. Como testemunham as colecçòes mais recentes, os informantes brasileiros parecem ter mais dificuldade em lembrar as suas versòes, vendo-se frequentemente obrigados a completá-las com grandes trechos em prosa ${ }^{43}$.

No catálogo que se segue, os títulos portugueses são acompanhados por títulos espanhóis tomados especialmente do catálogo sefardita do Prof. Armistead, mas inventei alguns para vários dos romances que existem só em Portugal e no Brasil. Para evitar repetiçòes desnecessárias, os títulos espanhóis só têm indicação de rima quando esta difere da portuguesa. Como o que aqui se pretende é catalogar o romanceiro brasileiro em linhas gerais, a bibliografia apresentada é mínima, limitando-se, sempre que possível, a obras principais. Para o Brasil, utilizo sobretudo os romanceiros de

onal, org. de Diego Catalán et al., pp. 233-75; "Conde Claros na Tradiçào Portuguesan, Quaderni Portoghesi, 11-12 (1982), 139-87; "Romanceiro Tradicional - IIma Poética da Comutaçãon, Caderno de Textos. 2." série, n." 1 (1989), 85-103; id., com a colab. de Cydnéa BouYer, Bibliografia do Folclore Brasileiro (Rio de Janeiro: Biblioteca Nacional, 1971).

${ }^{+2}$ Sobre as funções dos romances na vida dos informantes, V. COSTA FONTES, .Collecting Portuguese Ballads", Hispanic Balladry Today. The Albert Bates Lord Series in Oral Tradition 3, org. de Ruth H. Webber (New York-London: Garland, 1989), 14974: pp. 167-70.

43 V., por ex., LOPES, pp. 33, 41-42, 44-48, 70-75, 81-82, 106-07, 109-11, 135-36, 142-46, 142-56, 160, 223-25, 230-36, 239-40, 243-44, 247-48, 251-53; SEEGER, pp. 256-60; D. F. Xavier Alcoforado e M. del R. SuÁrez Albán, 'O Romanceiro Baiano- 1.1, 2.1 3, 3.2, 3.4, 4.1-2, 7.1, 8.1, 9.1, 15.2, 16.3-4, 18.1-2, 19.2, 19.4. 
António Lopes e Sílvio Romero. Para Portugal, precedidos por uma barra (/), o de Leite de Vasconcellos ${ }^{44}$ e o segundo volume da minha colecção transmontana, onde o leitor encontrará uma boa bibliografia luso-brasileira e pan-hispânica, embora, naturalmente, essa bibliografia se refira somente à temática presente nessa colectânea. As referências à Espanha colocam-se depois das duas barras (//), anotando-se especialmente as variantes galegas catalogadas por Ana Valenciano ${ }^{45}$, as castelhano-leonesas do catálogo de Diego Catalán ${ }^{46}$, e as catalãs publicadas por Milá ${ }^{47}$, a fim de assim representar as três principais zonas linguísticas desse país. Precedidas por três barras $(/ / /)$, as versões sefarditas são representadas pelo catálogo do Prof. Armistead $(=\mathrm{CMP})$, que contém uma bibliografia pan-ibérica e pan-europeia. Documento a tradição da América espanhola, colocada depois de quatro barras $(/ / / /)$, sobretudo por meio do livro de Gisela Beutler, extensa colecção que também inclui uma boa bibliografia hispano-americana ${ }^{48}$. Naturalmente, também foi necessário citar outras obras a fim de representar todas as áreas mencionadas sempre que possível.

\section{CATÁlogo}

B. Carolingios (baseados no Cantar de Gesta francês)

B1. A Morte de D. Beltrão (á) / La muerte de don Beltrán: Lopes, pp. 167-68 / VRP 17-18, 21-33, 984; TM, II, 1360 // CARG 13; RGL 12 /// CMP B4.

B2. Conde Claros e a Princesa Acusada (â) / Conde Claros y la princesa acusada: Lopes, pp. 161-63, 240-41, 243-44; Romero 7-8 / VRP 52, 54-55, 59, 69, 986; TM, II, 1335 // CARG 17; RGL 18; AFC 2973 /// CMP B10 //// Moya, II, 23-24.

B4. Conde Claros Vestido de Frade (â) / Conde Claros fraile: Lopes, pp. 149-50, 153 56, 159, 161; Romero 9 / VRP 52-70, 72-73, 75-91, 283, 501, 987; TM, II, 1336 / / CARG 18; RGL 19; Milá 258 /// CMP B12.

B7. O Conde Preso (á-o) / El conde preso: Lopes, pp. 125-26/VRP 38-44; TM, II, $1338 / /$ CARG 21; RGL $21 / / /$ CMP B24 //// México 24.1.

B10. Floresvento (â) / Floresvento: Lopes, pp. 231-32 / VRP 34- 37, 985; TM, 11, 1351 // CARG 11 /// Bénichou, p. 207.

4. V. a nota 29 .

45 Ana VAlenciano et al., Catálogo-Antología del Romancero de Galicia (Madrid: IMP; manuscrito).

46 Diego Catalá, Mariano de la Campa et al., Romancero General de León. Antología 1899-1989 (Madrid: SMP-Diputación Provincial de León, 1991), 2 vols.

4) Manuel MiLÁ y FonTANals, Romancerillo catalán: Canciones tradicionales (Barcelona: Álvaro Verdaguer, 1882).

4R Gisela BEUTLER, Estudios sobre el romancero español en Colombia en su tradición escrita y oral desde la época de la conquista basta la actualidad (Bogotá: Instituto Caro y Cuervo, 1977). 


\section{Históricos}

C4. Morte do Príncipe D. Afonso $(a ́+i-a) /$ La muerte del principe de Portugal: Romero 10 / Braga, II, 348-54.

C5. Morte do Príncipe D. João (á-a) / La muerte del príncipe don Juan: Magalhàes, p. 60 / VRP 6-16; TM, II, 1360-61 // CARG 10; RGL 10 /// CMP C14 //// Garrido de Boggs, pp. 81-82.

C7. Batalha de Lepanto (estróf. + i-a) / La batalla de Lepanto: Cascudo, História, pp. 433-34 / Braga, I, 4-6, II, 356-73.

\section{E. Biblico}

E1. A Criação (ou) / La creación (estróf.): Cf. Cascudo, Vaqueiros, pp. 252-53 / Azevedo, pp. 1-3; TM, II, 1340 // cf. RIG 286 (é-a) /// cf. CMP E1 //// cf. PPPR, pp. 64-66 (em décimas).

\section{H. Presos e cativos}

H1. A Rainha e a Sua Escrava (i-a) / Las hermanas reina y cautiva: Lopes, pp. 17475; Romero 22-23 / VRP 630-39; TM, II, 1368-69 // CARG 77; RGL 69; Milá 242, $242.1 / / /$ CMP H1.

H2. A Irmã Perdida (D. Bozo) (beptas., i-a) / Don Bueso y su bermana: Lopes, p. 62 / VRP 635 // CARG $78 a$ (pentas.), $78 b$ (beptas.); RGL 70 (pentas.; heptas.); Milá $250 / / /$ CMP H3 //// Beutler 173.

H3. O Cativo (é-a +estróf.) / El cautivo del renegado (é-a): CFP, pp. 345-49/VRP 626-28; TM, II, 1331 // CARG 62; RPM 214; Milá 267 /// CMP H6.

\section{Regresso do marido}

I1. Bela Infanta (polias.) / La vuelta del marido: Lopes, pp. 17-19, 21-25; Romero 1 / VRP 295-314, 316, 321, 323-44, 1005-06; TM, II, 1328-29 // CARG 76a; Milá 202.9-28 (á-a) /// Bosnia B7 (á-a).

12. Regresso do Marido (i) / La vuelta del marido: Portugal e Brasil: V. Bela Infanta (I1) // CARG 76a (vv. 13-30); Milá 203 /// CMP I1.

17. O Conde Flores (á) / El conde Antores: CFP, pp. 370-73 / VRP 92-96, 994; TM, II, 1337 // CARG 19; RGL 20 /// CMP I5.

19. A Volta do Navegante (á) / La vuelta del navegante. Lopes, pp. 51-52; Romero 2 / VRP 92-102, 994; TM, II, 1379 // CARG 74; RGL 66; Milá 206.1-22 /// CMP 18.

\section{J. Amor fiel}

J1. O Conde Ninbo (á) / El conde Niño: Lopes, pp. 47-48, 89-90, 247-48, 251-52 / VRP 235-48; TM, II, 1337-38 // CARG 25; RGL 25; Milá 206.23-32 /// CMP J1 //// Beutler 104-13. 
J2. A Aparição (i) / La aparición: Lopes, pp. 79, 82, 86; Romero 3 / VRP 354-55, 35761, 363-88, 400, 1008-10, 1023; TM, II, 1327-28 // CARG 58; RGL 54; Milá 227 / // CMP J2 //// México 99.1-5 e pp. 203-04.

J3. Afonso XII (i) / ¿Dónde vas, Alfonso XII? LRFB, p. 76 (m) // CARG 59; RGL 55; CM, IV, 270 (em cast.) /// Anahory 39 //// Beutler 175-87.

J10. A Confissão da Menina (ó) / La confesión de la niña: Romero 37 / Velhas Canções, pp. 183-84 (m).

J12. Eu Entrei pelo Mar Dentro (i-a) / El marinero y la bija del rey: Barroso, pp. 335-36.

\section{K. Amor infeliz}

K1. Donzela que se Fina de Amor (á) / La novia abandonada: Lopes, pp. 93-95, 248-49, 251-54; Romero 4 / VRP 55, 249-56; TM, II, 1346 // CARG 33; RIH 7-14, 76, 87 /// CMP K1.

K5. Não me Enterrem em Sagrado (á-o) / El testamento del enamorado: Lopes, p. 126; Romero 5 / VRP 38-43, 549-50, 697; TM, II, 1362 // CARG 39; RPM 311, 316-22, 349 /// CMP K12 //// Beutler 239-42.

K8. Febre Amarela (estróf.) / La fiebre amarilla: LRFB, pp. 65-70 (m) / VRP 8, 13, 354-55, 963-67; TM, II, 1348 // CRPG 47-48.

K11. Felizardo (á-o) / Felizardo: CFP, pp. 369-70.

\section{Esposa infeliz}

L1. O Conde Alarcos (i-a) / El conde Alarcos: Lopes, pp. 129-31, 135-38; Romero 6 / VRP 69, 130-82, 1001, 1022; TM, II, 1334 // CARG 27; RGL 28; Milá 237 /// CMP L1 //// Vicuña 7.

L2. O Parto em Terra Albeia (pentas., estróf.) / El parto en lejas tierras: Lopes, pp. 217-18, 221, 223-26; Romero 14/ VRP 552-53; TM, II, 1364-65 // CARG 73; RGL $65 / / /$ CMP L2.

L3. A Má Sogra (á) / La mala suegra: Lopes, pp. 109-11/ VRP 554-78; TM, II, 1358 // CARG 72; RGL 64; Milá 243 /// CMP L4 //// México 29.

L5. A Mulber Enganada (pentas., i-a) / La mujer engañada: CFP, pp. 359-60 / Braga, II, 276-77 // CARG 64; RGL 56; Milá 408 /// CMP L13 //// México 5.1.

L6. A Devota da Ermida (i-a) / La devota calumniada: Lopes, pp. 193-94 / VRP 66780; TM, II, 1343 // Vilhena, p. 137 (m; em port.).

L9. A Imperatriz Porcina (i-a) / La imperatriz Porcina: Cascudo, História, pp. 20711 / VRP 1020.

\section{Adúltera}

M1. Claralinda (polias.) / La Blancaniña (ó): LRFB, pp. 83-84 (m) / VRP 399-414, 1007; TM, II, 1333-34 // CARG 65; RGL 57; Milá 254 /// CMP M1 //// Beutler $145,147$. 
M2. Frei João (á-a) / La adúltera: Lopes, pp. 212, 214-15/ VRP 412-27, 1011; TM, II 1352-53 // CARG 95; RPM 132-33; Milá 359, cf. 221 /// CMP M3.

M5. Bernal Francês (i) / Bernal Francés: Lopes, pp. 78-79, 81-82, 85-86; Romero 3 / VRP 354-58, 360, 362-71, 1007-09; TM, II, 1330 // CARG 66; RGL 58; Milá 255 / // CMP M9 //// Beutler 141-44, 146.

M9. O Conde da Alemanba (estróf.) / El conde Alemán y la reina: Lopes, pp. 139-40, 142-46 / VRP 103-29, 198, 996-99; TM, II, 1336 // Vilhena, pp. 135-36 (em port.) /// CMP M13.

\section{N. Mulheres matadoras}

N1. Veneno de Moriana (estróf.) / El veneno de Moriana: Lopes, pp. 230, 232-37; Romero 19-20 / VRP 533-48; TM, II, 1378 // CARG 28; RGL 30; Milá 256 (principalmente em á-a) /// CMP N1.

N4. As Três Irmãzinhas (á) / El castigo del sacristán: Lopes, p. 101 / Braga, I, 29, 155-56, 166-67, II, 226-27 // RPE 97-100.

\section{O. Raptos e violações}

O2. Rico Franco (ê) / Rico Franco: CFP, pp. 309-11 / VRP 478; TM, II, 1371// CARG 54; RGL 50; Milá 551 /// CMP O2 //// PPPR, p. 195.

O3. O Cego (pentas., estróf.) / El raptor pordiosero: Lopes, pp. 207-10; Romero 1718 / VRP 517-32; TM, II, 1332 // CARG 49; RGL 44; cf. Milá 230 /// CMP O3.

O5. A Romeira e o Cavaleiro (i-a) / Una fatal ocasión: Lopes, pp. 55-56/VRP 42835, 1012-13; TM, II, 1371-72 // CARG 52; RGL 48.

\section{P. Incesto}

P1. Silvana (i-a) / Silvana: Lopes, p. 67 / VRP 482-83, 486, 489, 491, 501-03, 506-07, 514; TM, II, 1374-75 // CARG 69; RGL 60; Milá 272 /// CMP P1 //// Beutler 11422.

P2. Delgadinha (á-a) / Delgadina: Lopes, pp. 68, 70-75 / VRP 479-81, 483-90, 492514; TM, II, 1341-42 // CARG 70; RGL 61; Milá 29 (em cast.) /// CMP P2 //// Beutler 114-16, 118, 121-28.

\section{Q. Mulheres sedutoras}

Q1. Gerinaldo (i-o) / Gerineldo: Lopes, pp. 37-38, 41-42, 44-46,48 / VRP 257-74, 1004; TM, II, 1354-55 // CARG 26; RGL 26; Milá 269 /// CMP Q1 //// Beutler 96-103. 


\section{R. Mulheres seduzidas}

R4. A Fonte Fecundante (á-a) / La fuente fecundante. Lopes, pp. 149, 152-53, 155 , 158, 160-62; Romero 9 / VRP 53-54, 59, 69, 80-81, 86, 281-84, 987; TM, II, 1352 // CARG 30; RGL 31; Milá 258 /// CMP R4.

\section{S. Várias aventuras amorosas}

S2. Lizarda (estróf.) / Lizarda: CFP, pp. 302-09 / Braga, I, 432-42.

S12. A Morenita (estróf.) / La morenita: Romero 34 / TM, II, 1360.

\$23. O Chapim de El-Rei (estróf.) / El chapin del rey: LFS 21.1-2/ Garrett, I, 173-82.

\section{T. Enganos e artimanhas}

T1. O Cavaleiro Enganado (i-a) / El caballero burlado: Lopes, pp. 57-58, 62 / VRP 203-25; TM, II, 1332 // CARG 23; RGL 23; Milá 250 /// CMP T6 //// PPPR, p. 184.

T2. A Aposta Ganba (á) / La apuesta ganada: Lopes, pp. 148 (?), 152 (?) / VRP 7591, 987-93; TM, II, 1328 // CARG 50; RGL 45 /// MP 116.

T3. Deus te Guarde, Rosa (pentas., estróf.) / Linda pastora: Lopes, pp. 197-98; Romero 15 / VRP 884-87, 889-98, 900; TM, II, 1343 // CARG 79; RGL 72.

T4. O Baralho de Cartas (estróf.) / La baraja: Cascudo, História, pp. 230-36 / SJ 363-64 // CPM, II, 273, 305 //// Becco, p. 128.

\section{U. Romances sacros e oraçð̃es narrativas}

U4. Os Três Reis do Oriente (beptas, estróf.) / Adoración de los Reyes: Alvarenga, Melodias 63 (m) / TM, II, 1377 // CARG 145a-b(i-a), 145c (é-a), 145d (á-o); RPM 487, 499, 501; Pelay Briz, IV, 179-80.

U7. Nossa Senbora Lavadeira (estróf.) / La Virgen lavaba: CFP, pp. 531-32, 534-35 / TM, II, 1364 // CMG 269 //// Cruz-Sáenz, Romancero 22b, 22d-f.

U21. Paixào do Redentor (estróf.) / A Jesús nazareno: Neves, .Presença”, pp. 5859 / TM, II, 1364 // CPM, II, 333 (pentas.).

U29. Santa Catarina (á-a) / Santa Catalina: F. Fernandes, pp. 81-82 / VRP 754-58 / / CARG 91; RGL 80; Milá 24 /// CMP U9 //// PPPR, pp. 201-02.

U31. Santa Iria (pentas., á-a) / Santa Irene. Lopes, pp. 189-90; Romero 13 / VRP 438-42, 452-63; TM, II, 1372-73 // CARG 53; RGL 49; CM, IV, 253-54 (em cast.) /// CMP U10 //// MP, "América" 21.

U32. Santa Iria (beptas., á-a) / Santa Irene: LFS 11.3-11.3.1 / VRP 443-51, 466-70, 473, 477; TM, II, 1372 // CARG 53; RGL 49 /// CMP U10.

U34. Santo António Livra o Pai da Forca (estróf.) / San Antonio libera a su padre de la borca: CFP, pp. 384-89 / TM, II, 1373 // Alcázar, pp. 37-38 //// Campa, Spanish Folk Poetry, pp. 66-68. 
U35. Santo António e a Princesa de Leão (estróf.) / San Antonio resucita a la princesa de Portugal: Lopes, pp. 185-86 / Braga, II, 530-33, III, 157-59.

U37. Santa Teresa e o Pobrezinbo (estróf.) / Teresa de Jesús y Jesús de Teresa: CFP, pp. 389-91 / TM, II, 1373.

U40. O Lavrador da Arada (i-a) / El labrador caritativo: Lopes, pp.181-82 / VRP 81546; TM, II, 1357 // CARG 163; RPM 408-10.

U49. As Três Marias (â) / Las tres Marias: Romero, I, 367 / Braga, II, 382-83, 413, 422, 435, 456-57 // Coelho, *Romances galiciennes", p. 260; VN 109.1//// Vicuña 93-94.

U57. A Confissão da Noite (âo) / Señor mio Jesucristo (ó): Boiteux, p. 142 / TM, II, 1339 // RPM 480 //// Barros-Dannemann, p. 88 (no. 18).

\section{Morte personificada}

V2. D. Aleixo (i-a + estróf.) / Don Alejo: Lopes, pp. 102, 104-07; Romero 5 / VRP 54951 // CARG 60; FM 322; Milá 251.

\section{W. Animais}

W2. A Pulga e o Piolho (estróf.) / El piojo y la pulga: Romero 55 / TM, II, 1366-67 / / CRPG 137-45; CMPM 214; Milá 541-42 /// CMP W3 //// Beutler 272-79.

W5. O Macaco sem Rabo (ou) / La cola del lobo: Fontes, "Portuguese Folktales", pp. 30-31 / Azevedo, pp. 454-57 // Anón., “Cuentos», pp. 298-302 (mais prosa do que verso).

W6. O Canário (estróf.) / El canario de la princesa: Boiteux, p. 130 / VRP 864-71; TM, II, 1331.

w8. Uma História Grandiosa (estróf.) / Mentiras: Cf. Carvalho, pp. 178-81 / SJ 157 // Maciñeiro, p. 114; cf. Cuscoy, pp. 82-83; cf. Milá $581 / / / /$ cf. Beutler 290-92.

\section{Assuntos vários}

X1. Nau Catrineta (â) / La nao Cathrineta: Lopes, pp. 115-16, 120-23; Romero 11-12 e I, 319-20 / VRP 598-603, 1015-16; TM, II, 1362-63 // Milá 215-16.

X2. Infantina (i-a) / La infantina: Lopes, pp. 57, 61-62 / VRP 203-25; TM, II, 1356 // CARG 24; RGL 24; Milá 212-13 /// CMP X1 //// PPPR, pp. 183-84.

X5. Donzela Guerreira (ão, â) / La doncella guerrera (ó): Lopes, pp. 28-29, 33, 3536 / VRP 183-202, 1002-03; TM, II, 1345 // CARG 44; RGL 39; Milá 245 /// CMP X4 //// México 25.1.

X8. Mirandum (á) / Mambrü: LRFB, pp. 85-86 (m) / TM, II, 1359 // CARG 104; RGL 91; Milá 235 (e) /// CMP X19//// Beutler 248-59.

X20. Vida de Freira (estrōf.) / Las quejas de una monja: CFP, pp. 378-82 / TM, II, 1378.

$\mathrm{X} 21$. Vida de Frade (estróf.) / Las quejas de un monje: CFP, pp. 375-78 / Braga, II, 240-42. 
X26. A Filha do Rei de Espanha (â) / El buceador (polias. + ô): LFS 43.1-6 / VRP 662 /// CMP, III, 54.

\section{Y. Canções cumulativas}

Y1. Horas da Vida / A la una naci yo: F. Fernandes, p. 91 / TM, II, 1355 // Schindler, p. 33; cf. AFC 3294 (Dias da vida) /// CMP Y2 //// Becco, p. 147.

Y4. Ribeira Mota / El buen viejo: Romero 31 / TM, II, 1358-59 (Meus Senhores, Aqui Está o Vinho) // CPE, II, 79-80; AFC 408, 2350 /// CMP Y3 //// Armistead, "Hispanic Folk Literature", pp. 23-24.

Y5. A Formiga e a Neve / La cabrita: LFS 31.1-2 (m: p. 565 [31.1]) / TM, II, 1352 // Anón., "Cuentos", pp. 294-95//// Becco, pp. 99-101.

Y6. O Retrato da Namorada / El retrato: Cascudo, Vaqueiros, p. 102 (á) / TM, II, 1370-71// RPM 503 (pentas.); Milá 492, 495 /// CMP Y6 //// cf. Furt, I, 34-36, 252, II, no. 650 .

Y8. O Retrato do Menino Jesus / El retrato del niño Jesús: CFP, pp. $478-79$ (pentas.) / Ferreira, pp. 149-51, 196-98.

Y12. Os Mandamentos do Amor / Los mandamientos de amor. CFP, pp. 433-34/ GRPP 1050 // RPM 512-13, 524-25//// Campa, The Spanish Folksong, p. 30.

Y19. A Semana Amorosa / La semana amorosa: Braga, Cancioneiro, I, 488-89/ GRPP $1044-48$.

Y23. $A B C$ dos Amores / El ABC de amores: Boiteux, pp. 66-67 / Cantos, pp. 87-97.

\section{Z. Romances e canções infantis}

Z1. As Filhas da Condessa (estróf.) / Escogiendo novia (ê): LFS 22.1-7 / TM, II, 134950 // CARG 105; RGL 92; AFC 273 /// CMP S15//// Beutler 188-209.

Z2. Barca Bela (polias.) / La galera de la Virgen: CFP, p. $245 / \mathrm{TM}, \mathrm{II}, 1328 / / \mathrm{cf}$. CARG $142(a) / / / /$ cf. Becco, p. 71 (éo).

23. O Cordâo de Nossa Senbora (âo) / El cordón de la Virgen (ó + estróf.): Romero, II, 660 / VRP 848-50, 911; TM, II, 1339 // CMG 272.

Z4. Teresinba de Jesus (ào, á-o) / Teresita de Jesüs: Romero, II, 486 / TM, II, 1376.

Z6. Agora Baixou o Sol (estróf.) / Madanela: CFP, p. 536 / VRP 901-15; TM, II, 1324 // RS, p. 109 (H51).

Z9. O Tanglomanglo (estróf.) / Los perritos: Romero, II, 696-97 / Braga, Cancioneiro, II, 346-47 // Milá, .De la poesía", p. 393; Schindler, p. 107; CM, IV, 259 (em cast.) //// Beutler 287-89.

\section{TITULOS PORTUGUESES-ESPANHÓIS}

$\mathrm{ABC}$ dos Amores (cumul.) / El ABC de amores: Y23.

Afonso XII (í) / ¿Dónde vas, Alfonso XII?: J3.

Agora Baixou o Sol (estróf.) / Madanela: Z6. 
Aparição (î) / La aparición: J2.

Aposta Ganha (á) / La apuesta ganada: T2.

Baralho de Cartas (estróf.) / La baraja: T4.

Barca Bela (polias.) / La galera de la Virgen: Z2.

Batalha de Lepanto (estróf. + i-a) / La batalla de Lepanto: C7.

Bela Infanta (polias.) / La vuelta del marido: I1.

Bernal Francês (i) / Bernal Francés: M5.

Canário (estróf.) / El canario de la princesa: W6.

Cativo (é-a + estróf.) / El cautivo del renegado (é-a): H3.

Cavaleiro Enganado (i-a) / El caballero burlado: T1.

Cego (pentas., estróf.) / El raptor pordiosero: O3.

Chapim de El-Rei (estróf.) / El chapín del rey: S23.

Claralinda (polias.) / La Blancaniña (ó): M1.

Conde Alarcos (í-a) / El conde Alarcos: L1.

Conde Claros e a Princesa Acusada (á) / Conde Claros y la princesa acusada: B2.

Conde Claros Vestido de Frade (á) / Conde Claros fraile: B4.

Conde da Alemanha (estróf.) / El conde Alemán y la reina: M9.

Conde Flores (á) / El conde Antores: 17.

Conde Ninho (á) / El conde Niño: J1.

Conde Preso (á-o) / El conde preso: B7.

Confissão da Menina (ó) / La confesión de la niña: J10.

Confissão da Noite (ão) / Señor mío Jesucristo (ó): U57.

Cordão de Nossa Senhora (ão) / El cordón de la Virgen (ó + estróf.): Z3.

Criação (ou) / La creación (estróf.): E1.

D. Aleixo (i-a + estróf.) / Don Alejo: V2.

Delgadinha (á-a) / Delgadina: P2.

Deus te Guarde, Rosa (pentas., estróf.) / Linda pastora: T3.

Devota da Ermida (i-a) / La devota calumniada: L6.

Donzela Guerreira (ão, á) / La doncella guerrera (ó): X5.

Donzela que se Fina de Amor (á) / La novia abandonada: K1.

Eu Entrei pelo Mar Dentro (i-a) / El marinero y la hija del rey: J12.

Febre Amarela (estróf.) / La fiebre amarilla: K8.

Felizardo (á-o) / Felizardo: K11.

Filha do Rei de Espanha (á) / El buceador (polias. + ó): X26.

Filhas da Condessa (estróf.) / Escogiendo novia (é): Z1.

Floresvento (á) / Floresvento: B10.

Fonte Fecundante (á-a) / La fuente fecundante: R4.

Formiga e a Neve (cumul.) / La cabrita: Y5.

Frei João (á-a) / La adúltera: M2.

Gerinaldo (i-o) / Gerineldo: Q1.

Horas da Vida (cumul.) / A la una nací yo: Y1.

Imperatriz Porcina (i-a) / La imperatriz Porcina: L9.

Infantina (í-a) / La infantina: X2.

Irmã Perdida (D. Bozo) (heptas., í-a) / Don Bueso y su hermana: H2.

Lavrador da Arada (i-a) / El labrador caritativo: U40.

Lizarda (estróf.) / Lizarda: S2.

Macaco sem Rabo (ou) / La cola del lobo (esp. em prosa): W5.

Mandamentos do Amor (cumul.) / Los mandamientos de amor: Y12. 
Má Sogra (á) / La mala suegra: L3.

Mirandum (á) / Mambrú: X8.

Morenita (estróf.) / La morenita: S12.

Morte de D. Beltrão (á) / La muerte de don Beltrán: B1.

Morte do Príncipe D. Afonso (á + i-a) / La muerte del príncipe de Portugal: C4.

Morte do Príncipe D. João (ả-a) / La muerte del príncipe don Juan: C5.

Mulher Enganada (pentas., i-a) / La mujer engañada: L5.

Não me Enterrem em Sagrado (á-o) / El testamento del enamorado: K5.

Nau Catrineta (á) / La nao Cathrineta: X1.

Nossa Senhora Lavadeira (estróf.) / La Virgen lavaba: U7.

Paixão do Redentor (estróf.) / A Jesús nazareno: U21.

Parto em Terra Alheia (pentas., estróf.) / El parto en lejanas tierras: L2.

Pulga e o Piolho (estróf.) / El piojo y la pulga: W2.

Rainha e a Sua Escrava (i-a) / Las hermanas reina y cautiva: $\mathrm{H}$.

Regresso do Marido (i) / La vuelta del marido: 12.

Retrato da Namorada (cumul.) / El retrato: Y6.

Retrato do Menino Jesus (cumul.) / El retrato del niño Jesús: Y8.

Ribeira Mota (cumul.) / El buen viejo: Y4.

Rico Franco (é) / Rico Franco: O2.

Romeira e o Cavaleiro (i-a) / Una fatal ocasión: O5.

Santa Catarina (á-a) / Santa Catalina: U29.

Santa Iria (heptas., á-a) / Santa Irene: U32.

Santa Iria (pentas., á-a) / Santa Irene: U31.

Santa Teresa e o Pobrezinho (estróf.) / Teresa de Jesús y Jesús de Teresa: U37.

Santo António e a Princesa de Leão (estróf.) / San Antonio resucita a la princesa de Portugal: U35.

Santo António Livra o Pai da Forca (estróf.) / San Antonio libera a su padre de la horca: U34.

Semana Amorosa (cumul.) / La semana amorosa: Y19.

Silvana (í-a) / Silvana: P1.

Tanglomanglo (estróf.) / Los perritos: Z9.

Teresinha de Jesus (ào, á-o) / Teresita de Jesús: Z4.

Três Irmàzinhas (á) / El castigo del sacristán: N4.

Três Marias (á) / Las tres Marías: U49.

Três Reis do Oriente (heptas., estróf.) / Adoración de los Reyes: U4.

Uma História Grandiosa (estróf.) / Mentiras: W8.

Veneno de Moriana (estróf.) / El veneno de Moriana: N1.

Vida de Frade (estróf.) / Las quejas de un monje: X21.

Vida de Freira (estróf.) / Las quejas de una monja: X20.

Volta do Navegante (á) / La vuelta del navegante: 19.

\section{TITULOS ESPANHÓIS-PORTUGUESES}

$\mathrm{ABC}$ de amores (acumul.) / $\mathrm{O} A \mathrm{ABC}$ dos Amores: Y23.

Adoración de los Reyes (octos., estróf.) / Os Três Reis do Oriente: U4.

Adúltera (á-a) / Frei Joào: M2. 
A Jesús nazareno (estróf.) / Paixão do Redentor: U21.

A la una nací yo (acumul.) / Horas da Vida: Y1.

Aparición (1) / A Aparição: J2.

Apuesta ganada (á) / A Aposta Ganha: T2.

Baraja (estróf.) / O Baralho de Cartas: T4.

Batalla de Lepanto (estróf. + i-a) / Batalha de Lepanto: C7.

Bernal Francés (î) / Bernal Francês: M5.

Blancaniña (ó) / Claralinda (polias.): M1.

Buceador (polias. + ó) / A Filha do Rei de Espanha (á): X26.

Buen viejo (acumul.) / Ribeira Mota: Y4.

Caballero burlado (i-a) / O Cavaleiro Enganado: T1.

Cabrita (acumul.) / A Formiga e a Neve: Y5.

Canario de la princesa (estróf.) / O Canário: W6.

Castigo del sacristán (á) / As Três Irmãzinhas: N4.

Cautivo del renegado (é-a) / O Cativo (é-a + estróf.): H3.

Chapín del rey (estróf.) / O Chapim de El-Rei: \$23.

Cola del lobo (esp. en prosa) / O Macaco sem Rabo (ou): W5.

Conde Alarcos (i-a) / Conde Alarcos: L1.

Conde Claros y la princesa acusada (á) / Conde Claros e a Princesa Acusada: B2.

Conde Niño (á) / O Conde Ninho: J1.

Conde Antores (á) / O Conde Flores: 17.

Conde Alemán y la reina (estróf.) / O Conde da Alemanha: M9.

Conde Claros fraile (á) / Conde Claros Vestido de Frade: B4.

Conde preso (á-o) / O Conde Preso: B7.

Confesión de la niña (ó) / A Confissão da Menina: J10.

Cordón de la Virgen (ó + estróf.) / O Cordão de Nossa Senhora (ào): Z3.

Creación (estróf.) / A Criaçào (ou): E1.

Delgadina (á-a) / Delgadinha: P2.

Devota calumniada (í-a) / A Devota da Ermida: L6.

Don Bueso y su hermana (octos., í-a) / A Irmã Perdida (D. Bozo): H2.

Don Alejo (i-a + estróf.) / D. Aleixo: V2.

Doncella guerrera (ó) / Donzela Guerreira (ão, á): X5.

Escogiendo novia (é) / As Filhas da Condessa (estróf.): Z1.

Felizardo (á-o) / Felizardo: K11.

Fiebre amarilla (estróf.) / Febre Amarela: K8.

Floresvento (á) / Floresvento: B10.

Fuente fecundante (á-a) / A Fonte Fecundante: R4.

Galera de la Virgen (polias.) / Barca Bela: Z2.

Gerineldo (i-o) / Gerinaldo: Q1.

Hermanas reina y cautiva (i-a) / A Rainha e a Sua Escrava: H1.

Imperatriz Porcina (i-a) / A Imperatriz Porcina: 19.

Infantina (i-a) / Infantina: X2.

Labrador caritativo (i-a) / O Lavrador da Arada: U40.

Linda pastora (hexas., estróf.) / Deus te Guarde, Rosa: T3.

Lizarda (estróf.) / Lizarda: S2.

Madanela (estróf.) / Agora Baixou o Sol: Z6.

Mala suegra (á) / A Má Sogra: L3.

Mambrú (á) / Mirandum: X8. 
Mandamientos de amor (acumul.) / Os Mandamentos do Amor: Y12.

Marinero y la hija del rey (i-a) / Eu Entrei pelo Mar Dentro: J12.

Mentiras (estróf.) / Uma História Grandiosa: W8.

Morenita (estróf.) / A Morenita: S12.

Muerte de don Beltrán (á) / Morte de D. Beltrão: B1.

Muerte del príncipe de Portugal (á + í-a)/ Morte do Príncipe D. Afonso: C4.

Muerte del príncipe don Juan (á-a) / Morte do Príncipe D. João: C5.

Mujer engañada (hexas., í-a) / A Mulher Enganada: L5.

Nao Cathrineta (á) / Nau Catrineta: X1.

Novia abandonada (á) / Donzela que se Fina de Amor: K1.

Parto en lejanas tierras (hexas., estróf.) / O Parto em Terra Alheia: L2.

Perritos (estróf.) / O Tanglomanglo: Z9.

Piojo y la pulga (estróf.) / A Pulga e o Piolho: W2.

Quejas de un monje (estróf.) / Vida de Frade: X21.

Quejas de una monja (estróf.) / Vida de Freira: X20.

Raptor pordiosero (hexas., estróf.) / O Cego: O3.

Retrato (acumul.) / O Retrato da Namorada: Y6.

Retrato del niño Jesús (acumul.) / O Retrato do Menino Jesus: Y8.

Rico Franco (é) / Rico Franco: O2.

San Antonio libera a su padre de la horca (estróf.) / Santo António Livra o Pai da Forca: U34.

San Antonio resucita a la princesa de Portugal (estróf.) / Santo António e a Princesa de Leào: U35.

Santa Catalina (á-a) / Santa Catarina: U29.

Santa Irene (hexas., á-a) / Santa Iria: U31.

Santa Irene (octos., á-a) / Santa Iria: U32.

Semana amorosa (acumul.) / A Semana Amorosa: Y19.

Señor mío Jesucristo (ó) / A Confissào da Noite (ão): U57.

Silvana (i-a) / Silvana: P1.

Teresa de Jesús y Jesús de Teresa (estróf.) / Santa Teresa e o Pobrezinho: U37.

Teresita de Jesús (ào, á-o) / Teresinha de Jesus: Z4.

Testamento del enamorado (á-o) / Nào me Enterrem em Sagrado: K5.

Tres Marías (á) / As Três Marias: U49.

Una fatal ocasión (i-a) / A Romeira e o Cavaleiro: O5.

Veneno de Moriana (estróf.) / Veneno de Moriana: N1.

Virgen lavaba (estróf.) / Nossa Senhora Lavadeira: UT.

Vuelta del marido (polias.) / Bela Infanta: 11.

Vuelta del navegante (á) / A Volta do Navegante: 19.

Vuelta del marido (i) / Regresso do Marido: 12.

¿Dónde vas, Alfonso XII? (i) / Afonso XII: J3.

\section{Bibliografia}

$\mathrm{AFC}=$

Amades, Joan, Folklore de Catalunya. Cançoner (Cançons-refranysendevinalles), Barcelona: Editorial Selecta, 1951.

Alcázar, Ignacio del, Colección de cantos populares, Madrid: Antonio Aleu, 1910. 
Alcoforado, Doralice Fernandes Xavier, e María del Rosario Suárez Albán, "O Romanceiro Baiano", introd. de Idelette Muzart Ferreira dos Santos, Estudos Linguísticos e Literários (Salvador) n. 7 (Out. 1988), 47-130.

- . .O Romanceiro Galego*, Estudos Linguísticos e Literários (Salvador) $n .^{\circ} 7$ (Out. 1988), 131-46.

Almeida Garrett, João Baptista de: V. Garrett.

Alvarenga, Oneyda, Melodias Registradas por Meios Nào-Mecânicos, vol. I, São Paulo: Arquivo Folclórico da Discoteca Pública Municipal, 1946.

Amades, Joan: V. AFC.

Anahory $=\quad$ Anahory-Librowicz, Oro, Cancionero séphardi du Québec, 1, Montréal: Fonds FCAR, Collège du Vieux Montréal, 1988.

Anónimo, "Cuentos enlazados", Revista de Dialectología y Tradiciones Populares 2 (1946), 294-305.

Armistead, Samuel G., "A Critical Bibliography of the Hispanic Ballad in Oral Tradition (1971-79)", ERH, III, 199-310.

- "Bibliografía crítica del romancero (1979-1983). No prelo.

- "Bibliografía crítica del romancero (1984)", Actas del Congreso Romancero-Cancionero UCLA (1984), org. Enrique Rodríguez Cepeda e Samuel G. Armistead, 2 vols., Madrid: José Porrúa Turanzas, 1990, II, 447-530.

«Bibliografía del romancero (1985-1987)•, Pedro M. Piñero et al., orgs., El Romancero: Tradición y pervivencia a fines del siglo $X X$, pp. 749-89.

- "Hispanic Folk Literature Among the Isleños, Perspectives on Ethnicity in New Orleans, org. John Cooke e Mackie J.-V. Blanton, New Orleans: University of New Orleans, 1981, pp. 21-31.

Armistead, Samuel G.: V. também Bosnia, CMP, CMP III.

Armistead, Samuel G., e Manuel da Costa Fontes, orgs., Cancioneiro Tradicional de Trás-os-Montes, textos recolhidos por Samuel G. Armistead, Israel J. Katz, Zília Osório de Castro, e Candace Slater (manuscrito).

Armistead, Samuel G., e Joseph H. Silverman, "Uma Cançào Francesa na Tradição Brasileira: A Filha do Rei da Espanha", Ciência e Trópico 6 (1978), 315-16.

Azevedo, Álvaro Rodrigues de, Romanceiro do Arquipélago da Madeira, Funchal: *Voz do Povo*, 1880.

Barros-

Dannemann = Barros, Raquel, e Manuel Dannemann, El romancero chileno, [Santiago de Chile]: Universidad de Chile, 1970. 
Barroso, Gustavo, Ao Som da Viola (Folclore), nova ed., Rio de Janeiro: Departamento de Imprensa Nacional, 1949.

Becco, Horacio Jorge, Cancionero tradicional argentino, Buenos Aires: Librería Hachette, 1960.

Bénichou $=$ Bénichou, Paul, Romancero judeo-español de Marruecos, Madrid: Castalia, 1958.

- - El romance de la muerte del príncipe de Portugal en la tradición moderna", Nueva Revista de Filologia Hispánica 24 (1975), 11324.

Beutler, Gisela, Estudios sobre el romancero español en Colombia en su tradición escrita y oral desde la época de la conquista basta la actualidad, Bogotá: Instituto Caro y Cuervo, 1977.

Boiteux, Lucas Alexandre, "Poranduba Catarinense", Revista do Instituto Histórico e Geográfico Brasileiro 184 (1944), 1-92; reimpr.: Poranduba Catarinense, Florianópolis: Comissão Catarinense de Folclore, 1957.

Bosnia $=\quad$ Armistead, Samuel G., e Joseph H. Silverman, com a colab. de Biljana Sliivic Simsic, Judeo-Spanish Ballads from Bosnia, University of Pennsylvania Press Publications in Folklore and Folklife, Philadelphia: University of Pennsylvania Press, 1971.

Braga $=\quad$ Braga, Teófilo, Romanceiro Geral Português, 2. ${ }^{\text {a }}$ ed., 3 vols., Lisboa: Manuel Gomes, 1906, 1907; J. A. Rodrigues, 1909; reed. em fac-símile, com introd. de Pere Ferré, Lisboa: Vega, 1982 (1. ${ }^{\circ}$ vol.; os outros dois nào têm data).

- Cancioneiro Popular Português, 2. ${ }^{\mathrm{a}}$ ed., 2 vols., Lisboa: J.A. Rodrigues, 1911-13.

-. Romanceiro Geral Coligido da Tradição, Coimbra: Imprensa da Universidade, 1867.

Braga, Teófilo: V. também Cantos.

Cadilla de Martínez, María: V. PPPR.

Campa, Arthur León, Spanish Folk Poetry in New Mexico, Albuquerque: University of New Mexico Press, 1946; reimp. em HFSAC, 224 pp.

- The Spanish Folksong in the Southwest (=University of New Mexico Bulletin, Modern Language Series, vol. 4.1), Albuquerque: University of New Mexico Press, 1933; reimp. em HFSAC, 67 pp.

Cantos - Braga, Teófilo, Cantos Populares do Arquipélago Açoriano, Porto: Livraria Nacional, 1864; reed. em fac-símile, com Pref. de José de Almeida Pavão Jr., Ponta Delgada: Universidade dos Açores, 1982.

CARG = Valenciano, Ana, et al., Catálogo-Antología del Romancero de Galicia, Madrid: IMP. Manuscrito.

Carré Alvarellos, Lois: V. CRPG.

Carvalho, Uosé] Rodrigues, Cancioneiro do Norte, 3. ${ }^{2}$ ed., Rio de Janeiro: Ministério de Educação e Cultura; Instituto Nacional do Livro, 1967. 
Cascudo, Luís da Câmara, História da Literatura Brasileira, vol. VI: Literatura Oral, Rio de Janeiro: José Olympio, 1952.

- , 'Romanceiro", Dicionário de Literatura (Portuguesa, Brasileira, Galega), org. Jacinto do Prado Coelho, Vol. III, Porto: Figueirinhas, 1982, p. 961.

- Vaqueiros e Cantadores. Folclore Poético do Sertào de Pernambuco, Rio Grande do Norte e Ceará, Porto Alegre: Livraria Globo, 1939; reimp.: Rio de Janeiro, 1968.

Catalán, Diego, Samuel G. Armistead, e Antonio Sánchez Romeralo, orgs., El romancero en la tradición oral moderna: 1 er Coloquio internacional, Madrid: CSMP-Universidad de Madrid, 1972.

Catalán, Diego, J. Antonio Cid, Beatriz Mariscal, Flor Salazar, Ana Valenciano, e Sandra Robertson, CGR: Catálogo general del romancero. El romancero pan-bispánico: Catálogo general descriptivo, 4 vols., Madrid: SMP, 1982-88.

Catalán, Diego: V. também FM, RGL.

CFP $=\quad$ Costa, Francisco Augusto Pereira da, Folclore Pernambucano, Rio de Janeiro: Livraria J. Leite, 1908.

$\mathrm{CM}=\quad$ Giner Bauçà, Rafel, Cançoner popular de Mallorca, 4 vols., Introd. de Francesc de B. Moll, Palma de Mallorca: Editorial Moll, 1966-75.

CMG = Sampedro y Folgar, Casto, e José Filgueira Valverde, Cancionero musical de Galicia: Colección de la Sociedad Arqueológica de Pontevedra, 2 vols., Madrid: "El Museo de Pontevedra", 1942.

CMP $=\quad$ Armistead, Samuel G., com a colab. de Selma Margaretten, Paloma Montero, e Ana Valenciano, com transc. musicais editadas por Israel J. Katz, El romancero judeo-español en el Archivo Menéndez Pidal (Catálogo-indice de romances y canciones), 3 vols., Madrid: CSMP, 1978.

CMP, III = Armistead, Samuel G., "Antología de romances rarísimos", CMP, III, 7-56.

CMPM = Echevarría Bravo, Pedro, Cancionero musical popular manchego, Madrid: CSIC, 1951.

Coelho, Francisco Adolfo, *Romances galiciennes", Romania 2 (1873), 259-60.

Cortés, Carlos E.: V. HFSAC.

Cossío, José María: V. RPM.

Costa, Francisco Augusto Pereira da: V. CFP.

$\mathrm{CPE}=\quad$ Gil García, Bonifacio, Cancionero popular de Extremadura, 2 vols., vol. I, 2." ed.: Badajoz: Diputación, 1961; vol. II: Badajoz: Diputación, 1956.

Gil García, Bonifacio: V. também RPE. 
CPM $=\quad$ García Matos, Manuel, Cancionero popular de la provincia de Madrid, 3 vols., org. Marius Schneider e José Romeu Figueras (vols. I, II), Juan Tomás e José Romeu Figueras (vol. III), Barcelona-Madrid: CSIC, 1951-60.

CRPG $=\quad$ Carré Alvarellos, Lois, Romancero popular galego de tradizón oral, Porto: Junta de Província do Douro Litoral, 1959.

Cruz-Sáenz, Michèle S. de, Romancero tradicional de Costa Rica, pref. de Samuel G. Armistead, transc. musicais de Christina D. Braidotti, Newark, Delaware: Juan de la Cuesta, 1986.

Cuscoy, Luis Diego, Tradiciones populares, 2: Folklore infantil, La Laguna de Tenerife: CSIC, Instituto de Estudios Canarios en la Universidad de La Laguna, 1943.

Débax, Michelle, Romancero, Madrid: Alhambra, 1982.

Díaz Roig, Mercedes, El Romancero viejo, Madrid: Cátedra, 1981.

Díaz Roig, Mercedes: V. também México.

Di Stefano, Giuseppe, El Romancero: Estudio, notas, y comentarios de texto (Madrid: Narcea, 1973).

Echevarría Bravo, Pedro: V. CMPM.

ERH, I $=\quad$ Sánchez Romeralo, Antonio, Diego Catalán, e Samuel G. Armistead, orgs., El romancero boy: Nuevas fronteras, $2{ }^{\circ}$ Coloquio Internacional, University of California, Davis, Madrid: CSMP-University of CaliforniaGredos, 1979.

ERH, III = Samuel G. Armistead, Antonio Sánchez Romeralo, e Diego Catalán, orgs., The Hispanic Ballad Today: History, Comparativism, Critical Bibliography. 2nd International Symposium, University of Califormia, Davis, Madrid: CSMP-University of California-Gredos, 1979.

Ferreira $=$ Ferreira, P.e Manuel Juvenal Pita, O Natal na Madeira (Estudo Folclórico), Funchal: Edição da Junta do Distrito Autónomo, 1956.

F. Fernandes $=$ Fernandes, Florestan, "As 'Trocinhas' do Bom Retiro: Contribuição ao Estudo Folclórico e Sociológico da Cultura dos Grupos Infantis", Revista do Arquivo Municipal (S. Paulo) 113 (Março-Abril, 1947), 7-124.

FM = Catalán, Diego, com a colab. de María Jesús López de Vergara, Mercedes Morales, Aracelli González, María Victorina, e Ana Valenciano, La flor de la marañuela: Romancero general de las Islas Canarias, 2 vols., Madrid: CSMP-Gredos, 1969.

Fontes, Manuel da Costa, A Sephardic Vestige of the Ballad Floresvento, La Corónica 10 (1982), 196-201.

-A Transmissão Oral e as Progressivas Modificaçōes Éticas e Estéticas: O Caso de Vida de Freira, Atlântida 35 (1990), 17-54.

- "Barca Bela in the Portuguese Oral Tradition", Romance Philologv 37 (1983-84), 282-92. 
, "Collecting Portuguese Ballads", Hispanic Balladry Today, org. Ruth H. Webber, 149-74.

- "Lizarda: A Rare Vicentine Ballad in California", Romance Pbilology 32 (1978-79), 308-14.

- O Romanceiro Português: Indice Temático e Bibliogräfico / Portuguese and Brazilian Balladry: A Thematic and Bibliographic Index, Pref. de Samuel G. Armistead, Selecçào e Org. das Transcriçòes Musicais por Israel J. Katz. Manuscrito.

- , "Portuguese Folktales from California", Dissertação de Doutoramento, Los Angeles: University of California, 1975.

- "The Ballad of Floresvento and Its Epic Antecedents", Kentucky Romance Quarterly 32 (1985), 309-19.

- "The Batalha de Lepanto in the Portuguese Oral Tradition", Hispanic Review 47 (1979), 487-503.

- - "Vida de Freira en la tradición oral luso-brasileira", Estudios de folklore y literatura dedicados a Mercedes Díaz Roig, org. Beatriz Garza Cuarón e Yvette Jiménez de Báez, 641-65.

Fontes, Manuel da Costa: V. também SJ, TM.

Furt, Jorge M., Cancionero popular rioplatense. Lírica gauchesca, 2 vols., Buenos Aires: "Coni», 1923-25.

Galhoz, Maria Aliete Dores, "Resenha sobre a Actividade Editorial em Portugal nos Últimos Anos", Revista Lusitana (Nova Série) n. ${ }^{\circ} 8$ (1987), 177-84.

Galhoz, Maria Aliete Dores: V. também GRPP.

García Matos, Manuel: V. CPM.

Garrett $=$ Garrett, Joào Baptista de Almeida, Romanceiro, 3 vols., org. Fernando de Castro Pires de Lima, Lisboa: FNAT, 1963.

Garrido de Boggs, Edna, Versiones dominicanas de romances españoles, Ciudad Trujillo, República Dominicana: Pol Hermanos, 1946.

Garza Cuarón, Beatriz, e Yvette Jiménez de Báez, orgs., Estudios de folklore y literatura dedicados a Mercedes Díaz Roig, Estudios de Lingüística y Literatura 20, México, D.F.: El Colegio de México, 1992.

Gil García, Bonifacio: V. CPE.

Giner Bauçà, Rafel: V. CM.

GRPP = Galhoz, Maria Aliete Dores, Romanceiro Popular Português, 2 vols., Lisboa: INIC, 1987-88.

HFSAC $=$ Cortés, Carlos E., org., Hispanic Folklore Studies of Arthur Campa, New York: Arno Press, 1976.

Kundert, Hans: V. RS. 
LFS $=$

LRFB =

Maciñeiro $=$

México $=$

Milá =

MP -

MP, América
Lima, Jackson da Silva, O Folklore em Sergipe, 1: Romanceiro, Rio de Janeiro-Brasília: Livraria Editora Cátedra-Instituto Nacional do Livro, 1977.

Lima, Rossini Tavares de: V. LRFB.

Lopes, António, Presença do Romanceiro. Versōes Maranbenses, Rio de Janeiro: Editora Civilização Brasileira, 1967.

Lima, Rossini Tavares de, Romanceiro Folclórico do Brasil, São PauloRio de Janeiro: Irmãos Vitale, 1971.

Maciñeiro Pardo de Lama, Federico, "Literatura popular das terras da Capelada e da Faladora., Cuaderno de Estudios Gallegos 26 (1971), 95-116.

Magalhães, Celso de, A Poesia Popular Brasileira, org. Bráulio do Nascimento, Rio de Janeiro: Biblioteca Nacional, 1973.

Marques, José Joaquim Dias, "Nota Sobre o Início da Recolha do Romanceiro da Tradição Oral Moderna», Boletim de Filogia 32 (198892), 71-82.

Menéndez Pidal, Ramón, "A propósito del 'Romanceiro Português' de J. Leite de Vasconcellos", Actas: III Coloquio Internacional de Estudos Luso-Brasileiros, 2 vols., Lisboa: Imprensa de Coimbra, 1959, I, 493-99; reimp. em VRP, I, xi-xxi.

- Cómo vivió y cómo vive el Romancero, Valencia: La Enciclopedia Hispánica, 1945; reimp. em Estudios sobre el Romancero, Obras Completas, 11 (Madrid: Espasa-Calpe, 1973), pp. 403-62.

Menéndez Pidal, Ramón: V. também MP, MP “América».

Díaz Roig, Mercedes, e Aurelio González, Romancero tradicional de México, México, D.F.: UNAM, 1986.

Milá y Fontanals, Manuel, Romancerillo catalán: Canciones tradicionales, Barcelona: Álvaro Verdaguer, 1882.

- .De la poesía popular gallega", Romania 6 (1877), 47-75; reimp. em Obras completas, V: Opúsculos literarios, Segunda Série, Barcelona: Álvaro Verdaguer, 1893, pp. 363-99.

Moya, Ismael, Romancero: Estudios sobre materiales de la colección de folklore, 2 vols., Buenos Aires: Universidad de Buenos Aires, 1941.

Menéndez Pidal, Ramón, “Catálogo del romancero judío-español, Cultura Española 4 (1906), 1045-77; 5 (1907), 161-69; reimp. em El romancero: Teorias e investigaciones, Madrid: Páez, 1928, pp. 184-229, e em Los romances de América y otros estudios, Colección Austral 55, 6. ed., Madrid: Espasa-Calpe, 1958, pp. 114-79.

Menéndez Pidal, Ramón, "Los romances tradicionales en América:, Cultura Española 1 (1906), 72-111; reimp. em Los romances de América y otros estudios, Colección Austral 55, 6. ${ }^{2}$ ed., Madrid: EspasaCalpe, 1958, pp. 13-46. 
Nascimento, Bráulio do, "Conde Claros na Tradiçào Portuguesa", Quaderni Portoghesi 11-12 (1982), 139-87.

- ,Eufemismo e Criaçào Poética no Romanceiro Tradicional", El Romancero en la tradición oral moderna: 1er Coloquio Internacional, org. Diego Catalán et al., 233-75.

- .Pesquisa do Romanceiro Tradicional no Brasil", El romancero en la tradición oral moderna: 1er Coloquio internacional, org. Diego Catalán et al., pp. 5-83.

-, "Romanceiro Tradicional--Uma Poética da Comutação", Caderno de Textos $2 .^{\mathrm{a}}$ Série n. ${ }^{\circ} 1$ (1989), 85-103.

- .Um Romance Tradicional Entre Índios do Amazonas, no Século XX., ERH, I, 115-24.

Nascimento, Bráulio do, com a colab. de Cydnéa Bouyer, Bibliografia do Folclore Brasileiro, Rio de Janeiro: Biblioteca Nacional, 1971.

Neves, Guilherme Santos, "Presença do Romanceiro Peninsular na Tradição Oral do Brasil., Revista Brasileira de Folclore 1 (1961), 44-62.

Pelay Briz, Francesch, Cansons de la terra. Cants populars catalans, 5 vols., I: Barcelona: E. Ferrando Roca, 1866; II: Barcelona: Joan Roca y Bros, 1867; III: Barcelona: Alvar Verdaguer, 1871; IV, V: BarcelonaParis: Alvar Verdaguer-Maisonneuve, 1874-77.

Petersen, Suzanne H.: V. VN.

Piñero, Pedro M., Virtudes Atero, Enrique J. Rodríguez Baltanás, e María Jesús Ruiz, orgs., El Romancero: Tradición y pervivencia a fines del siglo XX. Actas del IV Coloquio Internacional del Romancero (Sevilla-Puerto de Santa María-Cádiz, 23-26 de Junio de 1987), SevillaCádiz: Fundación Machado-Universidad de Cádiz, 1989.

Pinto-Correia, João David, Romanceiro Tradicional Português, Lisboa: Comunicaçào, 1984.

PPPR = $\quad$ Cadilla de Martínez, María, La poesía popular en Puerto Rico, Madrid: Universidad de Madrid, 1933.

RGL = Catalán, Diego, Mariano de la Campa, et al., Romancero General de León: Antología 1899-1989, 2 vols., Madrid: SMP-Diputación Provincial de León, 1991.

RIG = Trapero, Maximiano, con la colab. de Elena Hernández Casañas, Romancero de la Isla de La Gomera, [Las Palmas]: Cabildo Insular de la Gomera, 1987.

RIH = Trapero, Maximiano, con la colab. de Elena Hernández Casañas, Romancero de la Isla del Hierro, estudio sobre la música por Lothar Siemens Hernández, Fuentes para el Estudio del Romancero: Serie Ultramarina, Madrid: IUISMP, 1985.

Romero $=$ Romero, Sílvio, Cantos Populares do Brasil, acompanhados de introdução e notas comparativas por Teófilo Braga, 2 vols., Lisboa: 
Nova Livraria Internacional, $1883 ; 2 .^{a}$ ed. com o título de Cantos Populares do Brasil, Rio de Janeiro-São Paulo: Livraria Clássica de Alves \& C. ${ }^{2}, 1897$; nova ed.: Cantos Populares do Brasil, org. Luís da Câmara Cascudo, 2 vols., Colecção Documentos Brasileiros 75 e 75-A, Rio de Janeiro: José Olympio, 1954.

RPE = Gil García, Bonifacio, Romances populares de Extremadura recogidos de la tradición oral, Badajoz: Diputación Provincial, 1944.

RPM = Cossío, José María de, e Tomás Maza Solano, Romancero popular de La Montaña: Colección de romances tradicionales, 2 vols., Santander: Sociedad Menéndez y Pelayo, 1933-34.

Kundert, Hans, "Romancerillo sanabrés", Revista de Dialectología y Tradiciones Populares, XVIII (1962), 37-124.

Sánchez Romeralo, Antonio, Diego Catalán, e Samuel G. Armistead, orgs., El romancero boy: Nuevas fronteras, $2{ }^{\circ}$ Coloquio Internacional, University of California, Davis, Madrid: CSMP-University of CaliforniaGredos, 1979.

Schindler, Kurt, Folk Music and Poetry of Spain and Portugal. Música y poesia popular de España y Portugal, Hildesheim-New York: Georg Olms, 1979; nova ed.: Música y poesía popular de España y Portugal, org. Israel J. Katz e Miguel Manzano Alonso, com a colab. de Samuel G. Armistead, Salamanca-New York: Centro de Cultura Tradicional, Diputación de Salamanca, e Hispanic Institute, Columbia University, 1991. Remeto ao texto suplementar (pp. 3-126).

Sampedro y Folgar, Casto: V. CMG.

Seeger, Judith, Count Claros: Study of a Ballad Tradition, The Albert Bates Lord Studies in Oral Tradition 4, New York: Garland, 1990.

Silva, José Calasans Brandão da, Júlio Santana Braga, e Maria Antonieta Campos Tourinho, Folclore Geo-Histónico da Babia e Seu Recôncavo, Rio de Janeiro: Campanha de Defesa do Folclore Brasileiro, 1972.

SJ = $\quad$ Fontes, Manuel da Costa, Romanceiro da Ilba de S. Jorge, Prefácio de Samuel G. Armistead e Joseph H. Silverman, Transc. musicais de Halim El-Dabh, Acta Universitatis Conimbrigensis, Coimbra: Universidade, 1983; ed. paralela em Fuentes para el Estudio del Romancero: Serie Luso-Brasileira 2, Madrid: CSMP, 1983.

Smith, C. Colin, Spanish Ballads, Oxford: Pergamon Press, 1964.

Trapero, Maximiano: V. RIG, RIH.

Fontes, Manuel da Costa, Romanceiro da Provincia de Trás-os-Montes (Distrito de Bragança), Coligido com a colab. de Maria-João Câmara Fontes, Pref. de Samuel G. Armistead e Joseph H. Silverman, Transc. musicais de Israel J. Katz, 2 vols., Acta Universitatis Conimbrigensis, Coimbra: Universidade, 1987.

Tomás, Pedro Fernandes: V. Velhas Canções. 
Valenciano, Ana: V. CARG.

Vasconcellos, José Leite de: V. VRP.

Veiga, S[ebastiào] P[hilippes] M[artins] Estácio da, Romanceiro do Algarve, Lisboa: Joaquim Germano de Sousa Neves, 1870.

Velhas Canções $=$ Tomás, Pedro Fernandes, Velhas Cançōes e Romances Populares Portugueses, Coimbra: F. França Amado, 1913.

Vicuña $=\quad$ Vicuña Cifuentes, Julio, Romances populares y vulgares recogidos de la tradición oral chilena, Santiago de Chile: Imprenta Barcelona, 1912.

Vilela, José Aloísio Brandão, Romanceiro Alagoano, org. Maria Thereza Wucherer Braga, Bráulio do Nascimento, Théo Brandão, e Maria Thereza Ribeiro Massow, Maceió: Edufal, 1983.

Vilhena, Maria da Conceiçào, "Literatura Oral em Cedillo e Herrera de Alcântara", Revista Lusitana (Nova Série) n. ${ }^{\circ} 10$ (1989), 125-56.

$\mathrm{VN}=\quad$ Petersen, Suzanne H., J. Antonio Cid, Flor Salazar, y Ana Valenciano, com a colab. de Bárbara Fernández e Concepción Vega, Voces nuevas del romancero castellano-leonés, AIER (Archivo Internacional Electrónico del Romancero) 1-2, dirigido por Diego Catalán, Madrid: SMP, 1982.

$\mathrm{VRP}=\quad$ Vasconcellos, José Leite de, Romanceiro Português, Nota preliminar de R. Menéndez Pidal, org. Manuel Viegas Guerreiro, Luís Filipe Lindley Cintra, Maria Aliete Farinho das Dores Galhoz, António Machado Guerreiro, Maria Ilda Andrade, e Maria Manuela Sacarrão, 2 vols., Acta Universitatis Conimbrigensis, Coimbra: Universidade, 1958-60.

Webber, Ruth H., Hispanic Balladry Today, The Albert Bates Lord Studies in Oral Tradition 3, New York-London: Garland, 1989.

\section{MANUEl DA COSTA FonTES}

Kent State University

El presente catálogo, que fue extraído de una obra todavía por publicar, mi $O$ Romanceiro Português e Brasileiro, clasifica los 89 romances conservados por la tradición oral brasileña. Aunque sólo se pretende dejar constancia de la existencia de cada romance en el Brasil, también se incluye una bibliografía que, a pesar de mínima, documenta paralelos portugueses, gallegos, castellanos, catalanes, sefarditas e hispanoamericanos.

The present catalogue, which was extracted from my still unpublished Portuguese and Brazilian Balladry, classifies the 89 ballads found in the Brazilian oral tradition. Although my main purpose is to document the existence of each ballad in Brazil, I have also included a short bibliography that lists Portuguese, Galician, Castilian, Catalan, Sephardic, and Spanish-American parallels. 